\title{
Incidência e perfil de susceptibilidade de bactérias isoladas do trato respiratório de pacientes em unidade de terapia intensiva
}

\author{
Incidence and susceptibility profile of bacteria isolated from the respiratory \\ tract of patients in intensive care unit
}

\author{
Rosângela Nunes Almeida ${ }^{1}$, Francisco Laurindo da Silva², Alison de Sousa Moreira ${ }^{3}$, João \\ Victor Almeida Vilanova 4
}

${ }^{1}$ Enfermeira. Doutoranda em Enfermagem (UFPI). Mestre em Biodiversidade, Ambiente e Saúde (UEMA). Docente da Universidade Estadual do Maranhão (UEMA). Caxias-MA, Brasil. E-mail: rnadasilva@hotmail.com *Autor para correspondência

${ }^{2}$ Biólogo, Doutor em Ciências Biológicas (Microbiologia) pela Universidade Federal de Minas Gerais-UFMG. Docente da Universidade Estadual do Maranhão-UEMA. Caxias-MA Brasil.E-mail: flspb@yahoo.com.br

${ }_{3}^{3}$ Enfermeiro. Especialista em Urgência e Emergência, Coordenador do Serviço de Atendimento Móvel de Urgência. São João do Sóter-MA, Brasil.E-mail: alisonsousa2012@bol.com.br

${ }^{4}$ Acadêmico de Direito. Centro Universitário de Ciências e Tecnologias do Maranhão (UniFacema). Caxias-MA, Brasil. E-mail: victor1998.vv@gmail.com

\author{
Palavras-chave \\ Incidência \\ Susceptibilidade \\ Bactérias \\ Trato respiratório \\ Unidade de Terapia Intensiva
}

\begin{abstract}
Objetivou-se analisar a incidência e o perfil de susceptibilidade de bactérias isoladas do trato respiratório de pacientes em Unidade de Terapia Intensiva de uma instituição hospitalar pública, no município de Caxias-MA. Trata-se uma pesquisa avaliativa, descritiva e experimental, com abordagem quantitativa. O cenário desta investigação foi o Hospital Geral Municipal "Gentil Filho", tendo sido realizado com 172 pacientes internados. Os dados foram obtidos mediante a realização de coletas microbiológicas do trato respiratório superior, para isolamento e identificação das bactérias e posterior análise do perfil de susceptibilidade aos antimicrobianos, no período de outubro de 2016 a maio de 2017. Compôs-se um banco de dados, no software STATA- Data Analysis and Statistical Software, que foram consolidados por meio de técnicas de estatísticas descritivas e apresentados sob a forma de tabelas. Além da realização de testes estatísticos como o Chi-quadrado (X2) de Pearson. Procedeu-se à discussão dos achados com base na literatura produzida sobre o tema. Os resultados apontaram que a maioria eram do sexo feminino, com 91(52,91\%), apresentando faixa etária $\geq 60,68(37,79 \%)$ e casados, com $86(50 \%)$. Quanto a incidência de bactérias, houve predomínio da $P$. aeruginosa, com $58(33,72 \%)$. Em relação ao perfil de susceptibilidade, percebeu-se que as bactérias encontradas, apresentaram resistência a algum tipo de antibiótico. Verificou-se ainda, resistência à amoxicilina + ácido clavunânico, classificando-as como produtoras de $\beta$-lactamases de espectro estendido. Portanto, enfatiza-se que o conhecimento das bactérias e do perfil de susceptibilidade permitirão uma antibioticoterapia correta.
\end{abstract}

\section{Keywords}

Incidence

Susceptibility

Bacteria

Respiratory tract

Intensive care unit
The aim of this study was to analyze the incidence and susceptibility profile of bacteria isolated from the respiratory tract of patients in the Intensive Care Unit of a public hospital, in the city of Caxias-MA. This is an evaluative, descriptive and experimental research, with a quantitative approach. The setting for this investigation was the Municipal General Hospital "Gentil Filho", having been carried out with 172 inpatients. The data were obtained by performing microbiological collections from the upper respiratory tract, for isolation and identification of bacteria and subsequent analysis of the susceptibility profile to antimicrobials, from October 2016 to May 2017. A database was composed, in STATA-Data Analysis and Statistical Software, which were consolidated using descriptive statistics techniques and presented in the form of tables. In addition to performing statistical tests such as Pearson's Chi-square (X2). The findings were discussed based on the literature produced on the topic. The results showed that the majority were female, with 91 (52.91\%), with an age range $\geq 60,68(37.79 \%)$ and married, with 86 (50\%). As for the incidence of bacteria, there was a predominance of $P$. aeruginosa, with $58(33.72 \%)$. Regarding the susceptibility profile, it was noticed that the bacteria found showed resistance to some type of antibiotic. There was also resistance to amoxicillin + clavunanic acid, classifying them as producers of extended spectrum B-lactamases. Therefore, it is emphasized that knowledge of the bacteria and the susceptibility profile will allow correct antibiotic therapy.

\section{INTRODUÇÃO}

As taxas de infecção hospitalar dentro das UTI variam entre 18 e 54\%, sendo cerca de 5 a 10 vezes mais elevada do que nas demais unidades de internação de um hospital. É responsável por 5 a 35\% de todas as infecções hospitalares 
por $90 \%$ de todos os surtos que ocorrem nessas unidades. As altas taxas de mortalidade nas UTI, usualmente variam entre 9 e 38\%, podendo alcançar 60\% devido à ocorrência comum de infecções nestes locais (OLIVEIRA; KOVNER; SILVA, 2010).

$\mathrm{Na}$ União Europeia, 4 milhões de pacientes contraem infecção hospitalar todos os anos, sendo as infecções do trato respiratório prevalentes e estão relacionadas com a utilização de técnicas invasivas. Ademais, estima-se que 20 a 30\% destas infecções sejam preveníveis. Além disso, os surtos de infecções neste setor hospitalar são frequentes, sendo os microrganismos gram negativos responsáveis por metade dos casos como o Acinetobacter baumannii e Pseudomonas aeruginosa e o Staphylococcus aureus, o agente gram positivo mais usual (CAVALEIRO, 2011).

Estudos realizados no Brasil e em outros países demonstram que a Pseudomonas aeruginosa está cada vez mais resistente aos antimicrobianos utilizados em seu tratamento. Desse modo, os antibióticos mais utilizados como opções terapêuticas para combater estas bactérias, como são os de carbapenêmicos e as cefalosporinas, os quais se classificam como maior espectro de ação, estão se tornando resistentes (FERREIRA; LARA, 2010).

Em um estudo realizado no município de Teresina-PI por Carvalho et al (2015) sobre a ocorrência de infecções hospitalares em UTI, detectou-se que a principal topografia das infecções hospitalares foram a respiratória, com 63 casos $(59,4 \%)$, e ainda que, os microrganismos mais frequentes nos episódios de infecção hospitalar com maior frequência foram a Pseudomonas aeruginosa, com 28 episódios (26,4\%), seguida da Klebsiela spp, com 26 episódios (24,5\%), logo após o Staphylococcus aureus, com 18 episódios (16,9\%), em menor frequência apareceu a bactéria Escherechia coli, com 11 episódios (10,5\%).

Assim, a incidência e o perfil de susceptibilidade são importantes instrumentos para a análise da resistência bacteriana, e representam um desafio para o sistema público de saúde. Além disso, buscam a garantia de acompanhamento sistemático dos indivíduos identificados como veiculadores de infecções hospitalares, assim como o desenvolvimento de ações referentes à promoção da saúde e à prevenção dessas patologias.

Uma outra situação preocupante, é seleção de cepas multirresistentes nas UTI, e que dificultam consideravelmente o tratamento de algumas infecções hospitalares. Ressalta-se que as principais bactérias multirresistentes responsáveis por estas complicações são: Staphylococcus aureus, resistente à oxacilina, enterobactérias produtoras de beta lactamase de espectro estendido (ESBL), bactérias do grupo CESP (Citrobacter spp, Enterobacter spp, Serratia spp e Providencia spp), Enterococcus, resistente à vancomicina, Klebsiella pneumoniae, produtora de carbapenemase e Acinetobacter sp, dentre outras (GOMES et al., 2014)

Madigan et al (2010) enfatizam que os antibióticos devem somente serem utilizados conforme cada agravo e condições do paciente. Desse modo, é válido salientar que, quanto menor for o uso indiscriminado, menores são as chances de ocorrência de resistência bacteriana.

A este respeito, Tosin (2001) ressalta que a resistência dos microrganismos aos antimicrobianos, tem aumentado consideravelmente, o que acarreta sérios problemas para a Saúde Pública, levando ao aumento dos gastos com a permanência dos pacientes nas unidades hospitalares. Assim, há necessidade do conhecimento destes patógenos e do perfil de susceptibilidade às drogas, para traçar alternativas de controle de infecções e substituição das drogas por outras em que os microrganismos sejam sensíveis à terapêutica, evitando-se dessa forma, a resistência à quimioterapia.

Mesmo com o advento do avanço cientifico e tecnológico da saúde, há uma grande preocupação por parte de gestores e profissionais de saúde em relação à infecção hospitalar, pois é crescente o reconhecimento de novos agentes infecciosos. No que concerne à UTI, essa inquietação é ainda maior, por se tratar de um ambiente de exposição dos pacientes aos riscos de contrair infecções, devido às condições clínicas existentes, que os tornam mais vulneráveis (LIMA; ANDRADE; HAAS, 2007).

Neste contexto, o objetivo deste estudo consiste na análise da incidência e do perfil de susceptibilidade de bactérias isoladas do trato respiratório de pacientes em Unidade de Terapia Intensiva de uma instituição hospitalar pública, no município de Caxias-MA.

\section{MATERIAL E MÉTODOS}

Trata-se de um estudo avaliativo, descritivo e experimental, com abordagem quantitativa. O cenário desta investigação foi o Hospital Geral Municipal (HGM) de Caxias "Gentil Filho", localizado no município de Caxias-MA, que tem área de $5.196,771 \mathrm{~km}^{2}$, situado na região leste do estado do Maranhão, a 374 quilômetros da capital São Luís, e a 70 quilômetros da capital piauiense, Teresina. Apresenta uma população estimada de 161.137 habitantes (IBGE, 2015).

O referido hospital foi escolhido por se tratar do maior centro hospitalar do município e contar com uma importante demanda ambulatorial e de internação, tanto em enfermarias, quanto na UTI. Ressalta-se que a $\mathrm{CClH}$ do referido hospital foi instaurada no ano de 2009. É comanda por uma enfermeira, que tem a responsabilidade técnica de controlar e/ ou monitorar todas as infecções que acometem aos pacientes.

Participaram da pesquisa os pacientes internados na UTI, 
independentemente da idade e das condições patológicas existentes, conforme cálculo amostral abaixo:

Para o cálculo do tamanho da amostra, considerou-se a prevalência nacional da infecção hospitalar nos hospitais públicos, que é de $18,4 \%$. Tendo uma população conhecida de 660 pacientes internados na UTI, para o ano de 2015, utilizouse a seguinte fórmula (FONSECA; MARTINS, 1996):

$$
n=\frac{N x \hat{p} x \hat{q} x\left(Z_{\alpha / 2}\right)^{2}}{\hat{p} x \hat{q} x\left(Z_{\alpha / 2}\right)^{2}+(N-1) x E^{2}}
$$

Onde:

$\mathrm{n}=$ Número de indivíduos na amostra

$Z_{-}(\alpha / 2)=$ Valor crítico que corresponde ao grau de confiança desejado.(Z_( $\alpha / 2)=1,96)$

$\hat{p}$ = Proporção populacional de indivíduos que pertence a categoria que se está interessado em estudar.

$\hat{q}=$ Proporção populacional de indivíduos que NÃO pertence à categoria que estamos interessados em estudar ( $q$ $=1-p)$.

$\mathrm{E}=$ Margem de erro ou Erro Máximo de Estimativa. Identifica a diferença máxima entre a proporção amostral e a verdadeira proporção Populacional ( $p$ )

Assim:

$\mathrm{n}=\quad 660 \times 0,184 \times 0,816 \times(1,96)^{2}$ $0,184 \times 0,816 \times(1,96)^{2}+659 \times(0,05)^{2}$

$\mathrm{n}=\quad \underline{660 \times 0,184 \times 0,816 \times 3,8416}$ $0,184 \times 0,816 \times 3,8416+659 \times 0,0025$

$$
\mathrm{n}=\frac{380,6835}{2,2242931} \Rightarrow \mathrm{n}=172
$$

Este tamanho de amostra ( $n=172$ ) permitiu estimar o parâmetro com margem de erro tolerável de $5 \%$ e nível de confiança de $95 \%$, na população finita de 660 pacientes internados na UTI no ano de 2015.

Evidencia-se que os critérios de inclusão dos sujeitos desta pesquisa foram: estar internado no mínimo há 72 horas na UTI do HGM de Caxias "Gentil Filho".

Destaca-se que o paciente, ao permitir a coleta das secreções biológicas, assinou o Termo de Consentimento Livre e esclarecido, ou quando, impossibilitado de responder por si, seu responsável o fez, medicante a assinatura do Termo de Assentimento.

Foram excluídos da investigação, os pacientes que não estavam em consonância com pelo menos um dos itens supracitados.
Enfatiza-se que, para garantir a total privacidade dos sujeitos no estudo, atribuiu-se o uso de siglas para identificação dos mesmos, e como todos eram pacientes, optou-se por usar a sigla "pcte" seguida de uma numeração cardinal, pela ordem de coleta do material microbiológico, com vistas na diferenciação cada sujeito. Assim, ficaram: pcte1, pcte2, pcte3... pcte172.

A obtenção dos dados ocorreu através da realização de coletas de espécimes clínicos do trato respiratório superior, pela via orofaríngea dos pacientes internados na UTI, as quais foram conduzidas ao Laboratório de Microbiologia e Imunologia do Centro de Estudos Superiores de Caxias/ Universidade Estadual do Maranhão (CESC/UEMA), colocados na presença de meios de cultura, e dispostos em estufa para crescimento bacteriano. Após o período de crescimento, foram identificadas as bactérias potencialmente patogênicas das vias aéreas dos pacientes e posteriormente estas foram posicionadas para interagirem com os antibióticos nos "discos de antibióticos" por 24 a 72 horas.

A coleta de dados ocorreu no período de outubro de 2016 a maio de 2017, aos pacientes internados na UTI. Assim, os usuários identificados, independestes da faixa etária, foram abordados pela pesquisadora neste setor hospitalar, quando foram convidados a participar da pesquisa e a assinaram o termo de consentimento livre e esclarecido. Ao paciente inconsciente, solicitou-se a autorização de seu respectivo responsável, por meio do termo de assentimento. Para a coleta do material biológico, utilizou-se um Swab estéril, onde foram obtidos os exsudatos. Os Swabs com os espécimes clínicos foram acondicionados em caixas térmicas tipo isopor, em tubos de ensaio com caldo infuso de cérebro e coração bovino ( $\mathrm{BHI}$ ) e encaminhados ao Laboratório de Microbiologia e Imunologia do Centro de Estudos Superiores de Caxias/ Universidade Estadual do Maranhão (CESC/ UEMA), para as análises bacterianas. Em seguida, os tubos contendo o material microbiológico foram colocados na estufa BOD (Biochemical Oxygen Demand), a uma temperatura de 370 C, por $24 \mathrm{~h}$, para crescimento bacteriano. Após o período de incubação, alíquotas do crescimento microbiano foram semeadas pela técnica de esgotamento com alça de platina nos meios de cultura ágar sangue (TSA-Tryptic Soy Agar + Sangue de Carneiro) e EMB Levine Agar (Agar Eosina Azul de Metileno), nas diluições $40 \mathrm{~g}$ e 37,5 g/ 1 Litro de água destilada, respectivamente. Em seguida, os meios foram postos em autoclave, para que pudessem ser esterilizados, a 121 C por 15 minutos. Após o processo de esterilização, fezse semeio nas placas, e as mesmas foram incubadas nas condições descritas acima.

As culturas que apresentaram crescimento e colônias sugestivas de bactérias, foram identificadas por meio de análise macroscópica, provas bioquímicas (catalase, 
coagulase, teste da optoquina, bacitracina, Rugai, oxidase e outros) ou testes sorológicos.

A análise microbiológica e o perfil de susceptibilidade foram realizados paralelamente à coleta do material biológico. Os testes de susceptibilidade obedeceram a técnica Kirb-Bauer ou E-teste, de acordo com CLSI (2017). Para tanto, os discos de antibióticos utilizados encontravam-se em conformidade com as sugestões expressas pelos padrões adotados nos Estados Unidos, e indicados pela ANVISA. Assim, foram referenciados no grupo $A$ as drogas de primeira escolha para o antibiograma, no grupo $B$ as de segunda escolha e no grupo $C$ as drogas suplementares, testadas quando o primeiro e segundo grupos não se mostraram eficazes. Para amostras de urina, recomenda-se a adição das drogas que estão descritas no grupo Urinário. Entretanto, como os microrganismos não pertenciam ao grupo Urinário, utilizou apenas os grupos A, B e C. Enfatiza-se, com o seguimento dos critérios desse fluxograma, a racionalidade de antibióticos. Ademais, a recomendação original é a de que se o microrganismo testado for sensível aos antibióticos do grupo A, apenas estes resultados sejam liberados, assim, as drogas do grupo $B$ são testadas apenas quando se verificar alto índice de resistência ao grupo $A$, o mesmo raciocínio aplicado ao grupo $\mathrm{C}$ em relação ao grupo $\mathrm{B}$.

As suspensões microbianas foram preparadas com base na escala 0,5 de Mac Farland ( $\left.1 \times 10^{6} \mathrm{UFC} / \mathrm{ML}\right)$, as quais foram semeadas em placas de Petri do tamanho $900 \times 900 \mathrm{~mm}$, com meio de cultura ágar Muller-Hinton. Esses semeios ficaram em repouso por 10 minutos e somente após esse período de tempo, é que foram depositados discos de antibióticos ou Eteste sobre o inóculo bacteriano. As placas foram incubadas em estufa BOD a 37 C por $24 \mathrm{~h}$. A interpretação do teste foi realizada mediante a utilização de um halômetro.
Dessa forma, as bactérias foram classificadas em: " $\mathrm{S}$ " para susceptível, "I" intermediário e " $R$ " resistente, de acordo o tamanho do halo formado nos discos de antibióticos ou Eteste, tomando como base o Clinical and Laboratory Standards Institute (CLSI, 2017).

Os discos de antibióticos utilizados, obedeceram a classificação das bactérias de acordo com o método de colocação, sendo então, denominadas: Gram negativas; estando neste grupo as proteobactérias (Escherichia coli, Salmonella e Shingella) e as Enterobacteriaceae (Pseudomonas, Moraxella, Helicobacter, Stenotrophomonas, Bdellovibrio, Legionella) e Gram positivas (Bacilos, Estreptococos, Estafilococos, Enterococos, Listeria, etc.), como descritivo abaixo:

Compôs-se um banco de dados, no software STATA- Data Analysis and Statistical Software, versão 10.0 for Windows), posteriormente, foram consolidados por meio de técnicas de estatísticas descritivas (frequências absoluta e relativa) e apresentados sob a forma de tabelas, no software Excel (versão 2013), para uma posterior análise e interpretação dos mesmos. Além da realização de testes estatísticos como o Chiquadrado (X2) de Pearson, para verificação de significância estatísticas.

Por fim, foram coletados espécimes clínicos das vias aéreas superiores dos pacientes na UTI, as quais foram identificadas as bactérias potencialmente patogênicas e foi realizado a análise do perfil de susceptibilidade. De posse da lista nominal das bactérias e da classificação em: Sensível, intermediário e Resistente, procedeu-se a discussão dos achados com base na literatura produzida sobre o tema.

O projeto foi aprovado pelo Comitê de Ética em Pesquisa do Centro de Estudos Superiores de Caxias, na Universidade Estadual do Maranhão (CESC-UEMA), com certificado de

Quadro1: Relação de Antimicrobianos, conforme classificação de bactérias pelo método de Gram. Caxias-MA, 2017.

\begin{tabular}{|l|l|}
\hline GRAM NEGATIVO & GRAM POSITIVO \\
\hline Ampicilina $10 \mathrm{mcg}$ & Cefepime $30 \mathrm{mcg}$ \\
\hline Amicacina $30 \mathrm{mcg}$ & Ciprofloxacina $5 \mathrm{mcg}$ \\
\hline Amoxilina + Ac.Clavulânico $30 \mathrm{mcg}$ & Clorofenicol $30 \mathrm{mcg}$ \\
\hline Ceftazidima $30 \mathrm{mcg}$ & Clindamicina $2 \mathrm{mcg}$ \\
\hline Cefalotina $30 \mathrm{mcg}$ & Eritromicina $15 \mathrm{mcg}$ \\
\hline Cefepime $30 \mathrm{mcg}$ & Gentamicina $10 \mathrm{mg}$ \\
\hline Cefoxitina $30 \mathrm{mcg}$ & Oxacilina $1 \mathrm{mcg}$ \\
\hline Cefuroxima $30 \mathrm{mcg}$ & Penicilina-G $10 \mathrm{U} . I$ \\
\hline Ciprofloxacina $5 \mathrm{mcg}$ & Rifampicina $5 \mathrm{mcg}$ \\
\hline Gentamicina $10 \mathrm{mcg}$ & Sulfazotrim $25 \mathrm{mcg}$ \\
\hline Meropenem $10 \mathrm{mcg}$ & Tetraciclina $30 \mathrm{mcg}$ \\
\hline Sulfazotrim $25 \mathrm{mcg}$ & Vancomicina $30 \mathrm{mcg}$ \\
\hline
\end{tabular}


Apresentação para Apreciação Ética (CAAE) no 57134616.0.0000.5554.

\section{RESULTADOS E DISCUSSÃO}

As tabelas que serão descritas e analisadas a seguir referem-se aos dados coletados a partir das informações de 172 pacientes internados na UTI do Hospital Geral Municipal (HGM) de Caxias “Gentil Filho", em Caxias-MA.

Na população constituída por 172 pacientes, 91 (52,91\%) dos participantes eram do sexo feminino e 81 (47,09\%) masculino. Este resultado coincide com o estudo de Gomes et al (2014), corroborando com os elementos supracitados neste trabalho, no que refere ao sexo de pacientes hospitalizados em UTI, sendo a predominância de mulheres internadas $(52,4 \%)$.

Dentre os investigados, a maioria $68(37,79 \%)$ encontravase na faixa etária $\geq 60$, portanto, considerados idosos. Dessa forma, predominou-se a população de idosos. Os dados encontrados por Villas Boas e Ruiz (2004) apresentaram resultados semelhantes a este achado, ao evidenciar que a faixa etária predominante de pacientes internados em hospitais de grande porte, e com o setor de UTI instalados, foram os $\geq 60$ anos, fato que os expõem aos riscos de contraírem infecção hospitalar.

Somando-se a isto, Werner e Kuntsche (2000) enfatizam que, os idosos além de necessitarem de maiores cuidados, devido suas condições clínicas, os mesmos estão mais susceptíveis a adquirir infecção hospitalar, por causa das alterações fisiológicas do envelhecimento, pela realização de procedimentos considerados invasivos, e ainda pela diminuição da resposta imunológica.

Além disso, ressalta-se que, os idosos têm maiores chances de desencadearem complicações e co-morbidades, por suas condições patológicas existentes, e ainda, estando presente a realização de exames diagnósticos de forma

Tabela 1. Distribuição dos dados sócio demográficos de pacientes internados na Unidade de Terapia Intensiva do Hospital Geral Municipal de Caxias "Gentil Filho". Caxias-MA, 2017.

\begin{tabular}{lcc}
\hline VARIÁVEIS & n & \% \\
Sexo & & \\
Feminino & 91 & 52,91 \\
Masculino & 81 & 47,09 \\
Total & $\mathbf{1 7 2}$ & $\mathbf{1 0 0 , 0}$ \\
Faixa etária & & \\
$18-23$ & 6 & 3,49 \\
$24-29$ & 7 & 4,07 \\
$30-35$ & 8 & 4,65 \\
$36-41$ & 12 & 6,98 \\
$42-47$ & 10 & 5,81 \\
$48-53$ & 20 & 11,63 \\
$54-59$ & 48 & 25,58 \\
$\geq 60$ & 68 & 37,79 \\
& 04 &
\end{tabular}

Total

\section{Estado Civil}

Solteiro(a)

Casado(a)

Viúvo(a)

União estável

Divorciado(a)
172

$\begin{array}{cc}18 & 10,47 \\ 86 & 50,00 \\ 34 & 19,77 \\ 25 & 14,53 \\ 9 & 5,23\end{array}$

Total

Fonte: Pesquisa direta, 2017. 
vagarosa, tais adventos, podem aumentar os riscos de infecção hospitalar.

Quanto ao estado civil, 86 (50,00 \%) eram casados. Essa realidade está com conformidade com Freitas, Kimura e Ferreira (2007), em um estudo sobre o estado civil de pacientes em UTI, em que foram encontrados resultados semelhantes.

A tabela 2 refere-se aos dados provenientes a partir das coletas de materiais microbiológicos obtidas do trato respiratório superior de pacientes internados na UTI do HGM "Gentil Filho", e demonstra a incidência das bactérias potencialmente patogênicas.

Através da análise dos dados, percebeu-se que as bactérias mais incidentes foram a $P$. aeruginosa, com $58(33,72 \%)$, seguida da S. aureus, com 41(23,83\%), K. spp, com $29(16,86 \%)$, S. epidermidis, com $18(10,47 \%)$, E. coli, com $12(6,98 \%)$, A. baumannii, com $8(4,65 \%)$ e a K. pneumoniae, com $6(3,49 \%)$. A $P$. aeruginosa é um microrganismo que pode ser encontrado nos mais diversos ambientes, especialmente no hospitalar. Essa bactéria é oportunista e portanto, é comum o seu isolamento a partir de espécimes clínicos, sobretudo, em pacientes que estejam sob terapia intensiva. Esse resultado coincide com o de Silva, Werneck e Henriques (2012), tendo a bactéria P. aeruginosa mais prevalente na UTI.

Conforme Cavaleiro (2011), são frequentes os surtos de infecções ocorridos na UTI, em decorrência de microrganismos Gram negativos, como as bactérias Acinetobacter, P. aeruginosa, e por Gram positivas como o $S$. aureus. O que representa um aumento do risco e tempo de permanência dos pacientes nesses ambientes.

A $K$. pneumoniae também esteve entre os agentes microbianos encontrados em pacientes da UTI (SILVA; WERNECK; HENRIQUES, 2012). Quanto ao A. baumannii isolado no Swab nasal, que é encontrado colonizando a orofaringe de pessoas sadias, também é capaz de se proliferar durante a hospitalização e vir a causar infecção hospitalar. Ressalta-se, que a mesma pode sobreviver em superfícies úmidas, incluindo equipamentos de terapia respiratória (CABRAL; POVEDA, 2008).

Dentre os microrganismos mencionados, houve o predomínio de bactérias gram-negativas, que representam grande relevância para a saúde, principalmente por estarem relacionadas a diversas patologias, como as infecções do trato respiratório, e podem levar o indivíduo às internações em UTI.

Ao analisar as Unidades Pediátricas de um Hospital Público de Rondônia-RO, no período de janeiro a julho do ano de 2010, revelou-se as bactérias predominantes foram as $P$. aeruginosa (47\%), seguida da E. coli (25\%), Enterobacter (20\%) e S. spp (8,3\%) (GRILLO et al., 2013).

Resultado semelhante foi encontrado por Radji et al

Tabela 2. Distribuição da incidência de bactérias isoladas do trato respiratório de pacientes internados na Unidade de Terapia Intensiva. Caxias-MA, 2017.

\section{Secreção traqueal}

\begin{tabular}{lcc}
\cline { 2 - 3 } & $\mathrm{n}$ & $\%$ \\
\hline Bactérias & 58 & 33,72 \\
\hline P. aeruginosa & 41 & 23,83 \\
S. aureus & 29 & 16,86 \\
S. epidermidis & 18 & 10,47 \\
E. coli & 12 & 6,98 \\
A. baumannii & 8 & 4,65 \\
K. pneumoniae & 6 & 3,49 \\
\hline Total & $\mathbf{1 7 2}$ & $\mathbf{1 0 0 , 0}$ \\
\hline
\end{tabular}

Fonte: Pesquisa direta, 2017. 
(2011), quando avaliaram a prevalência de bactérias em uma UTI de um hospital da Indonésia, no período de janeiro de 2009 a março de 2010, onde os mais prevalentes isolados foram: P. aeruginosa (26,5\%), seguido de $K$. pneumoniae $(15,3 \%)$ e $S$. epidermidis (14,9\%).

A tabela 3 apresenta aos dados sobre o perfil de susceptibilidade das bactérias potencialmente patogênicas encontradas no trato respiratório superior dos pacientes em UTI do Hospital Municipal "Gentil Filho", aos antimicrobianos, para tanto, os resultados foram expressos em " $\mathrm{S}$ " sensíveis, "I" intermediários e " $R$ " resistentes, conforme halo de inibição formado nos discos de antibióticos.

De acordo com a tabela acima, percebeu-se que as bactérias encontradas apresentavam resistência a alguns antimicrobianos. Na tabela estão cepas de $P$. aeruginosa e outros microrganismos, apresentando resistência à amicacina, que hoje é o um antibiótico muito utilizado na terapia de pacientes acometidos por infecções, em que a bactéria seja multirresistente a vários antimicrobianos. Outro dado preocupante é a resistência que alguns desses agentes apresentaram à amoxicilina + ácido clavulânico. Esse último perfil de susceptibilidade pode supostamente incluir essas bactérias, no grupo das produtoras de $\beta$-lactamases de espectro estendido, tipo carbapenemases. Para Neves et al (2011) a potência dos antimicrobianos estar ameaçada, e isso deve-se principalmente ao mecanismo de resistência ocorrido com os antibióticos.

O aumento da resistência bacteriana, especialmente entre bactérias potencialmente patogênicas, tem levado a um aumento na necessidade de novos fármacos e novas classes de antibióticos, para infecções adquiridas em hospitais (BRITO; CORDEIRO, 2012).

Tabela 3. Distribuição do perfil de susceptibilidade de bactérias aos antimicrobianos, de pacientes internados na Unidade de Terapia Intensiva. Caxias-MA, 2017.

\begin{tabular}{|c|c|c|c|c|c|c|c|}
\hline \multicolumn{8}{|c|}{ Bactérias* } \\
\hline & P.aeruginosa & S. aureus & $K . \mathrm{spp}$ & S. epidermidis & E. coli & A. baumannii & K. pneumoniae \\
\hline \multicolumn{8}{|c|}{ Antimicrobianos } \\
\hline Ampicilina & $S$ & - & $\mathrm{R}$ & - & $\mathrm{R}$ & $\mathrm{R}$ & $\mathrm{R}$ \\
\hline Amicacina & $\mathrm{R}$ & - & $\mathrm{R}$ & - & $\mathrm{R}$ & $S$ & $\mathrm{R}$ \\
\hline Amoxilina & $\mathrm{R}$ & - & $\mathrm{R}$ & - & $\mathrm{R}$ & $\mathrm{R}$ & $\mathrm{R}$ \\
\hline Ceftazidima & $\mathrm{R}$ & - & $\mathrm{S}$ & - & I & $\mathrm{R}$ & $S$ \\
\hline Cefalotina & $S$ & - & - & - & - & I & - \\
\hline Ceftriaxona & I & $\mathrm{S}$ & $\mathrm{R}$ & S & $\mathrm{R}$ & I & $\mathrm{R}$ \\
\hline Cefoxitina & $S$ & - & - & - & - & - & - \\
\hline Cefuroxima & I & - & $\mathrm{R}$ & - & $\mathrm{R}$ & $S$ & $\mathrm{R}$ \\
\hline Ciprofloxacina & $S$ & $\mathrm{R}$ & I & $\mathrm{R}$ & I & $\mathrm{R}$ & I \\
\hline Gentamicina & $\mathrm{R}$ & $\mathrm{R}$ & $\mathrm{R}$ & $\mathrm{R}$ & $\mathrm{R}$ & $\mathrm{R}$ & $\mathrm{R}$ \\
\hline Meropenem & $S$ & - & $\mathrm{S}$ & - & $\mathrm{S}$ & $\mathrm{R}$ & $S$ \\
\hline Clorofenicol & S & $\mathrm{R}$ & $\mathrm{S}$ & $\mathrm{R}$ & $\mathrm{S}$ & $S$ & $S$ \\
\hline Clindamicina & - & I & $\mathrm{S}$ & $S$ & $\mathrm{~S}$ & - & $\mathrm{S}$ \\
\hline Eritromicina & - & $\mathrm{R}$ & - & $\mathrm{R}$ & - & - & - \\
\hline Penicilina & - & $\mathrm{R}$ & - & $\mathrm{R}$ & - & - & - \\
\hline Rifampicina & - & $\mathrm{S}$ & - & $S$ & - & - & - \\
\hline Tetraciclina & - & $\mathrm{R}$ & $\mathrm{S}$ & $\mathrm{R}$ & $\mathrm{S}$ & $S$ & $S$ \\
\hline Vancomicina & - & $\mathrm{I}$ & - & I & - & - & - \\
\hline
\end{tabular}

Fonte: Pesquisa direta, 2017.

* Perfil de susceptibilidade das bactérias encontradas nos pacientes 54,55,68,79,81,86,112. 
Os achados de Zanol, Picoli e Morsch(2010) sobre resistência bacteriana, enfatizam a necessidade de novos fármacos urgentemente, para as bactérias $S$. aureus, $A$. baumannii, K. pneumoniae, $P$. aeruginosa e espécies de Enterobacter. Ademais, a despeito dessa necessidade, somente duas classes de antibióticos foram introduzidas na saúde desde 1963, quando o ácido nalidíxico foi aprovado, que foram a oxazolidinona linezolina, em 2000, e o lipopeptídeo cíclico daptomicina, em 2003.

Além do mais, outros antibióticos foram lançados contra bactérias resistentes, pela Agência Americana Reguladora de Alimentos e Medicamentos (Food and Drug AdministrationFDA), que são: Tigeciclina, Tetraciclina de última geração, aprovadas em 2005; Retapamulina, Pleuromotilineo aprovadas em 2008; Cetfarolina, Cefalosporina, aprovadas em 2010 (MULLARD, 2011).

Neste contexto, o uso racional de antibióticos torna-se imprescindivel para redução e/ou prevenção de infecções hospitalares, ou seja, associadas à assistência nos serviços de saúde. Acrescentando-se a isto, é necessário que a prescrição medicamentosa seja regulada conforme ao profissional que a prescreve, que é o médico, e ainda, que seja controlada por uma equipe multidisciplinar que tenham conhecimento do princípio ativo, efeitos, doses e horários apropriados, para evitar o surgimento de bactérias multirresistentes (BERNARDES, 2004).

A análise dos dados da tabela acima, priorizou-se as recomendações do CLSI (2017), que classificam as bactérias em sensíveis, intermediárias e resistentes conforme de agentes antimicrobianos, sendo referenciados no grupo $A$, as drogas de primeira escolha para o antibiograma, no grupo $B$, as de segunda escolha e no grupo $C$, as drogas suplementares, testadas quando o primeiro e segundo grupos não se mostrarem eficazes.

Assim, objetiva-se uma escolha mais racional de antibióticos. A recomendação original é a de que se o microrganismo testado for sensível aos antibióticos do grupo A, apenas estes resultados sejam liberados, assim, as drogas do grupo B, são testadas apenas quando se verificar alto índice de resistência ao grupo $A$, o mesmo raciocínio aplicado ao grupo $C$ em relação ao grupo $B$. Assim, o antibiograma deve ser realizado para determinar a sensibilidade bacteriana a essas e outras drogas, visando uma antibioticoterapia adequada e específica.

A tabela 4 evidencia a distribuição das bactérias identificadas no trato respiratório superior, de pacientes internados na UTI, em função do percentil de cepas classificadas em sensíveis, intermediárias e resistentes aos antimicrobianos, e revela que dos microrganismos isolados, houve o predomínio da resistência aos antimicrobianos.

Com base nos achados acima, pode-se observar que as bactérias isoladas e identificadas apresentaram-se resistentes aos antimicrobianos, com $77(44,21 \%)$. Outro dado importante é número bem significativo de cepas apresentando susceptibilidade a vários antimicrobianos, especialmente a P. aeruginosa. Outra bactéria, que atualmente tem sido muito isolada de espécimes clínicos de pacientes hospitalizados é a $K$. pneumoniae, que de acordo com estudo, a quantidade de cepas que apresentaram resistência aos antimicrobianos, não foi significativo. Pesquisa desenvolvida por Seibertet et al (2013), corrobora com os resultados desta investigação, ao evidenciar que as bactérias encontradas em uma UTI de um hospital de urgência do Piauí, apresentavam resistência aos antibióticos.

De acordo com a Organização Mundial de Saúde (OMS) a resistência bacteriana representa uma ameaça à Saúde Pública, e isso se deve principalmente ao uso inadequado de antibióticos (BRASIL, 2012). Por isso, é fundamental conhecer o mecanismo de resistência bacteriana, com vistas ao desenvolvimento de estratégias para evitar as cepas cada vez mais resistentes (OGUTLU et al., 2014).

Ademais, para Barros et al (2012), o uso inadequado de antibióticos favorece a proliferação de bactérias, aumentando as infecções destes microrganismos entre os pacientes. Dessa forma, enfatiza-se a importância da utilização desses fármacos com cautela, pelos profissionais, com vistas a prevenir a resistência de patógenos. Assim, a prescrição dos antimicrobianos devem seguir alguns critérios, como a gravidade da patologia, a eficácia dos medicamentos, o uso antecipado de antibióticos, entre outros.

Os antimicrobianos são fármacos com a propriedade de suprimir o crescimento dos patógenos ou destruí-los, sendo denominados de bacteriostáticos e bactericidas, respectivamente, cuja utilização na assistência terapêutica, melhoram o prognóstico das doenças infecciosas. Entretanto, Carneiro et al (2011) também salientam que seu emprego crescente e indiscriminado é o principal fator relacionado com a emergência de cepas microbianas resistentes. $E$ ainda, que doses inadequadas, em duração prolongada, resultam em seleção bacteriana e aumento da resistência bacteriana.

Otimizar a prescrição de antimicrobianos no âmbito hospitalar representa um desafio constante, que envolve uma ação multiprofissional, com vistas a redução da utilização inapropriada destes antibióticos, e consequentemente diminuição da pressão seletiva, que conduz ao aparecimento de resistência. Estima-se que, 25 a $50 \%$ da prescrição desses fármacos seja feita erroneamente, o que também contribui para aumento dos gastos na saúde (SOUZA et al., 2008).

No ambiente hospitalar, a prática abusiva de antimicrobianos, contribui para o aumento da morbidade, mortalidade, prolongamento do tempo de internação e elevação dos custos do tratamento. Dessa maneira, é 
Tabela 4. Distribuição de bactérias, conforme percentual de cepas sensíveis, intermediárias e resistentes aos antimicrobianos, de pacientes internados na Unidade de Terapia Intensiva. Caxias-MA, 2017.

\section{Perfil de susceptibilidade}

Sensível Intermediária Resistente Total

$\begin{array}{llllllll}\mathrm{n} & \% & \mathrm{n} & \% & \mathrm{n} & \% & \mathrm{n} & \%\end{array}$

\begin{tabular}{|c|c|c|c|c|c|c|c|c|}
\hline \multicolumn{9}{|l|}{ Bactérias } \\
\hline P. aeruginosa & 26 & 15,11 & 10 & 5,81 & 22 & 12,80 & 58 & 33,72 \\
\hline S. aureus & 11 & 6,39 & 13 & 7,55 & 17 & 9,89 & 41 & 23,83 \\
\hline$K . \mathrm{spp}$ & 5 & 2,91 & 10 & 5,81 & 14 & 8,14 & 29 & 16,86 \\
\hline S. epidermidis & 7 & 4,07 & 3 & 1,75 & 8 & 4,65 & 18 & 10,47 \\
\hline E. coli & 3 & 1,75 & 2 & 1,16 & 7 & 4,07 & 12 & 7,98 \\
\hline A. baumannii & 2 & 1,16 & 1 & 0,58 & 5 & 2,91 & 8 & 4,65 \\
\hline K. pneumoniae & 2 & 1,16 & 1 & 0,58 & 3 & 1,75 & 6 & 3,49 \\
\hline Total & 55 & 32,55 & 40 & 23,24 & 77 & 44,21 & 172 & 100,0 \\
\hline
\end{tabular}

Fonte: Pesquisa direta, 2017.

indispensável a adoção de medidas que visam à redução do emprego errado de antibióticos, o que oferece subsídios para diminuição das taxas de resistência (CARNEIRO et al., 2011).

A resistência aos antimicrobianos tem conduzido ao desenvolvimento de infecções hospitalares, devido ao aumento das internações, elevando os gastos com a permanência dos pacientes no setor hospitalar. Na UTI, essa problemática poderá ser ainda maior, principalmente pelo fato de haver várias intervenções ou terapêuticas invasivas, que requerem o uso frequente de amplo espetro de antibióticos, e as muitas vezes são usados sem uma prévia análise do medicamento mais apropriado para tal finalidade (PAIM; SOLDATELLI; LORENZINI, 2013).

O consumo excessivo de antibióticos na UTI favorece o aparecimento de microrganismos multirresistentes e de cepas resistentes. Em decorrência disso, um grupo de bactérias denominado ESKAPE (Enterococcus faecium, Staphylococcus aureus, Klebsiella pneumoniae, Acinetobacter baumannii, Pseudomonas aeruginosa, and Enterobacter spp) foram descritas como os principais microrganismos causadores de infecções hospitalares (CURCIO, 2011).

De acordo com a ANVISA a definição de multirresistência, é muito variável e depende da complexidade de cada hospital. Normalmente, uma bactéria é definida como multirresistente quando apresenta resistência a duas ou mais classes de antimicrobianos. Assim, as principais bactérias multirresistentes que causam infecções infecção hospitalar são: S. aureus meticilina resistente (MRSA), Enterococos resistentes à vancomicina (VRE), cepas produtoras de $\beta$ lactamases de espectro estendido (ESBLs, extended-spectrum $\beta$-lactamases) e bactérias Gram-negativas, como Acinetobacter spp e $P$. aeruginosa, resistentes aos carbapenens (BRASIL, 2012).

Nas bactérias $P$. aeruginosa, foram identificadas enzimas que promovem a hidrólise das cefalosporinas, penicilinas e carbapenêmicos, as quais são denominadas de carbapenemase ou metalo- $\beta$-lactamases, e conferem resistência a esses antimicrobianos, em torno de $80 \%$ a apenas dois antibióticos, Ampicilina e Meropenem, e resistência superior a $60 \%$ para seis dos dez antibióticos testados (MACHADO et al., 2011).

Em um estudo realizado Deliberali et al (2011) em pacientes internados na UTI de um Hospital em Porto Alegre, verificou-se que as prevalências de bacilos Gram-negativos não fermentadores foram a $P$. aeruginosa e a $A$. baumannii como os microrganismos mais frequentes, isoladas da secreção traqueal. Quando analisado o perfil de susceptibilidade, constatou-se consideráveis índices de 
resistência, sendo encontrados 32,8\% e 37,1\% resistentes a Imipenem e Meropenem, respectivamente.

Os estudos de Deliberali et al (2011) demonstraram que, a resistência de Acinetobacter ao Imipenem vem aumentando, sendo que, em 2009, encontraram-se taxas de resistência de 16,7\%, e em 2011 foram, essa taxa aumentou para 32,8\%.

Ao analisar o perfil de resistência da bactéria $S$. aureus de um Hospital em Pernambuco-PE, detectou-se os seguintes padrões de resistência: penicilinas (95\%), tetraciclinas (32\%), Eritromicina (21\%), Gentamicina (16\%), Cefoxitina (11\%), Oxacilina (11\%), Sulfametoxazol/Trimetoprima (11\%), Clorafenicol (11\%), Clindamicina (5\%) (CARACIOLO et al. 2012).

Avaliando o perfil de resistência de $K$. spp. em um hospital público em São Paulo-SP, certificou-se que houve crescimento da resistência aos antimicrobianos desse microrganismo. Dos antibióticos testados, quase todos apresentaram aumento da resistência, com exceção da Cefoxitina e Meropenem (OLIVEIRA et al., 2011).

Quando avaliado o perfil de susceptibilidade da $P$. aeruginosa em uma UTI de um Hospital da Indonésia, no período de janeiro de 2009 a março de 2010, verificou-se que alta taxa de resistência para Cefalexina (95,3\%), Cefotaxima $(64,1 \%)$ e Ceftriaxona $(60,9 \%)$, as duas últimas classificadas como cefalosporinas de terceira geração (GRILLO et al., 2013).

\section{CONSIDERAÇÕES FINAIS}

Identificou-se que a maioria eram do sexo feminino, apresentando idade maior ou igual a 60 anos e casados.

Quanto à seção sobre a incidência de bactérias no trato respiratório dos pacientes, notou-se que a bactéria mais incidente foi a P. aeruginosa.

Em relação ao perfil de susceptibilidade, constatou-se que as bactérias $P$. aeruginosa, $S$. aureus, $K$. spp, $S$. epidermidis, $E$. coli, $A$. baumannii e $K$. pneumoniae, encontradas nos pacientes caracterizados pelos números $54,55,68,79,81,86$ e 112, apresentaram resistência a algum tipo de antibiótico. Ademais, todas as bactérias encontradas apresentaram resistência à amoxicilina + ácido clavunânico, que as classificam no grupo das produtoras de $\beta$-lactamases de espectro estendido.

Nesse sentido, é válido mencionar que por fatores diversos, como o aparecimento de resistência aos antimicrobianos, é imprescindível a utilização racional de antibióticos, com vistas a redução dos gastos em tratamentos com esses fármacos nos pacientes, bem como, a propulsão aos mecanismos de resistência, o que seria uma ameaça à medicina.

No tocante a análise referente ao perfil de susceptibilidade frente ao percentil de cepas sensíveis, intermediárias e resistentes, verificou-se que a maioria mostraram-se resistentes aos antimicrobianos. É válido ressaltar ainda, que a $P$. aeruginosa apresentou significativa sensibilidade a vários antimicrobianos.

Esta pesquisa amplia o conhecimento sobre a incidência e o perfil de susceptibilidade aos antimicrobianos e oferece elementos para contribuir para o processo de cuidado à saúde, visando melhorar a qualidade da assistência prestada ao paciente, promovendo o uso seguro e racional de medicamentos e subsidiando práticas que evitem cada vez a ocorrência de infecção hospitalar. Assim, o conhecimento das bactérias e do perfil de susceptibilidade permitirão uma antibioticoterapia correta.

\section{REFERÊNCIAS}

BARROS, L.M et al. Prevalência de micro-organismo e sensibilidade antimicrobiana de infecções hospitalares em unidade de terapia intensiva de hospital público no Brasil. Rev Ciênc Farm Básica Apl., v.33, n.3, p. 429-435, 2012.

BERNARDES, R.C.; JORGE, A.O.C.; LEÃO, M.V.P. Sensibilidade à oxacilina, vancomicina, e teicoplanina de Staphylococcus coagulase-positivos isolados de pacientes hospitalizados em São José dos Campos. Revista Biociências, v.10, p.7378, 2004.

BRASIL. Agência Nacional de Vigilância Sanitária (ANVISA). Uso Racional de Medicamentos - temas selecionados. 2012.

BRITO, M. A.; CORDEIRO, B. C. Necessidade de novos antibióticos. J Bras Patol Med Lab, v. 48, n. 4, p. 247-249, agosto 2012.

CABRAL, E.V.; POVEDA, V.B. Perfil microbiológico e resistência bacteriana em unidade de tratamento intensivo. J Nurs UFPE on line [internet], v. 2, n.4, p.357-64, 2008.

CARACIOLO, F. B. et al. Antimicrobial resistance profile of Staphylococcus aureus isolates obtained from skin and soft tissue infections of outpatients from a university hospital in Recife -PE, Brazil. Anais Brasileiros de Dermatologia, vol.87, n.6, p.857-861, 2012.

CARNEIRO, M. et al. Antibiotic prescription in a teaching hospital: a brief assessment. Revista da Associação Médica Brasileira, vol.57, n.4, p. 421-424, 2011.

CARVALHO, M. R. et al. Incidência de bactérias multirresistentes em uma unidade de terapia intensiva. Revista Interdisciplinar NOVAFAPI, v. 8, n. 2, p. 75-85, abr. mai. Jun, 2015.

CAVALEIRO, P. L. G. Prevenção da Infecção Nosocomial nas Unidades de Cuidados Intensivos. Dissertação (Mestrado em Medicina) - Universidade do Porto, Porto, Portugal, 
2011.

CLINICAL AND LABORATORY STANDARDS INSTITUTE (CLSI). Profile of susceptibility to antigrams, 2017.

CURCIO, D. J. Antibiotic prescription in intensive care units in Latin America. Revista Argentina de Microbiologia, vol. 43, n.3, p. 203-211, 2011.

DELIBERALI, B. et al. Prevalência de bacilos Gram-negativos não fermentadores de pacientes internados em Porto Alegre-RS. Jornal Brasileiro de Patologia e Medicina Laboratorial, vol.47, n.5, p. 529-534, 2011.

FERREIRA, H.; LARA, E.R. Pseudomonas aeruginosa: Um alerta aos profissionais de saúde. São Paulo: Rev Panam Infectol. v. 12, n.2, p. 44-50. Abr./Jun. 2010.

FONSECA, J. S.; MARTINS, G. A. Curso de Estatística. 6. ed. São Paulo: Atlas, 1996.

FREITAS, K.S.; KIMURA, M.; FERREIRA, K.A.S.L. Necessidades de familiares de pacientes em unidades de terapia intensiva: análise comparativa entre hospital público e privado. Rev Latino-am Enfermagem, v.15, n.1, p.84-92, Jan-Fev, 2007.

GOMES, A.C. et al. Caracterização das infecções relacionadas à assistência em Unidade de Terapia Intensiva. Rev enferm UFPE on line, Recife, v. 8, n. 6, p.1577-85, jun., 2014.

GRILLO, T.R.S.V. et al. Incidência bacteriana e perfil de resistência a antimicrobianos em pacientes pediátricos de um hospital público de Rondônia, Brasil. Revista de Ciências Farmacêuticas Básica e Aplicada, v.34, n.1, p.117123, 2013.

IBGE. Instituto Brasileiro de Geografia e Estatística. Cidades. [s.l.:s.n.], 2015. Disponível em: <http:// www.ibge.gov.br/cidades>. Acesso em: 02 de abril de 2017.

LIMA, M.E.; ANDRADE, D.; HAAS, V.J. Avaliação prospectiva da ocorrência de infecção em pacientes críticos de Unidade de Terapia Intensiva. Rev Bras Ter Intensiva, v.19, n.3, p.342-7, 2007.

MACHADO, G.M. et al. Ocorrência e perfil de sensibilidade a antimicrobianos em Pseudomonas aeruginosa e Acinetobacter sp. em um hospital terciário, no sul do Brasil. Revista da Sociedade Brasileira de Medicina Tropical, vol.44, n.2, p. 168-172, 2011.

MADIGAN, M.T. et al. Microbiologia de Brock. Porto Alegre: Artmed, 2010.

MULLARD, A. 2010 FDA Drug Approvals. Nat Rev Drug Disc, v. 10, p. 82-5, 2011

NEVES, P. R. et al. Pseudomonas aeruginosa multirresistente: um problema endêmico no Brasil. J Bras Patol Med Lab, v. 47, n. 4, p. 409-20, 2011.

OGUTLU, A. et al. Effects of Carbapenem Consumption on the Prevalence of Acinetobacter Infection in Intensive Care Unit Patients. 13. ed. Sakarya, Turquia: Annals of Clinical
Microbiology and Antimicrobials, 2014.

OLIVEIRA, A.C.; KOVNER, C.T.; SILVA, R.S. Infecção hospitalar em unidade de tratamento intensivo de um hospital universitário brasileiro. Rev Latino-Am. Enfermagem, v.18, n. 2, p. 233-239, 2010.

OLIVEIRA, C. B. S. et al. Frequência e perfil de resistência de Klebsiella spp em um hospital universitário de Natal/RN durante 10 anos. Jornal Brasileiro de Patologia e Medicina Laboratorial, v.47, n.6, p.589-594, 2011.

PAIM; SOLDATELLI; LORENZINI. Resistência antimicrobiana de uma instituição de médio porte da região nordeste do Rio Grande do Sul. Biblioteca Lascasas, v. 9, n. 3, 2013.

RADJI, M. et al. Antibiotic sensitivity pattern of bacterial pathogens in the intensive care unit of Fatmawati Hospital, Indonesia. Asian Pacific Journal of Tropical Biomedicine, v.1, n.1, p. 39-42, 2011.

SILVA, A.R.A.; WERNECK, L.; HENRIQUES, C.T. Dinâmica da circulação de bactérias multirresistentes em unidades de terapia intensiva pediátrica do Rio de Janeiro. Rev Epidemiol control infect [Internet], v. 2, n.2, p.41-45, 2012.

SOUZA, H. P. et al. Auditoria no uso de antimicrobianos em enfermaria cirúrgica. Revista do Colégio Brasileiro de Cirurgiões, v.35, n.4, p. 216-220, 2008.

TOSIN, I. Avaliação do modo de disseminação da resistência bacteriana a antibacterianos nos hospitais brasileiros. São Paulo, s.n, p. [137] p. ilus., tab., 2001.

VILLAS BOAS, P. J. F.; RUIZ, T. Ocorrência de infecção hospitalar em idosos internados em hospital universitário. Rev Saúde Pública, v.38, n.3, p. 372-8, 2004.

WERNER, H.; KUNTSCHE, J. Infection in the elderly: what is different? Z Gerontol Geriatr, v.33, p.350-8, 2000.

ZANOL, F. M.; PICOLI, S. U.; MORSCH, F. Detecção fenotípica de metalobetalactamase em isolados clínicos de Pseudomonas aeruginosa de hospitais de Caxias do Sul. J Bras Patol Med Lab, v. 46, n. 4, p. 309-14, 2010.

\author{
Submissão: 03/03/2020 \\ Aprovado para publicação: 14/03/2020
}

